\title{
Phenotype and envelope gene diversity of nef-deleted HIV-I isolated from long-term survivors infected from a single source Lachlan Gray ${ }^{1,2}$, Melissa J Churchill ${ }^{1}$, Jasminka Sterjovski1,3, Kristie Witlox ${ }^{1,4}$, Jennifer C Learmont ${ }^{5}$, John S Sullivan ${ }^{5,6}$, Steven L Wesselingh ${ }^{1,2,3}$, Dana Gabuzda7,8, Anthony L Cunningham ${ }^{9}$, Dale A McPhee ${ }^{2,10}$ and Paul R Gorry*1,2,3
}

Address: ${ }^{1}$ Macfarlane Burnet Institute for Medical Research and Public Health, Victoria, Australia, ${ }^{2}$ Department of Microbiology and Immunology, University of Melbourne, Parkville, Victoria, Australia, ${ }^{3}$ Department of Medicine, Monash University, Melbourne, Victoria, Australia, ${ }^{4}$ Department of Pathology and Immunology, Monash University, Melbourne, Victoria, Australia, ${ }^{5}$ Australian Red Cross Blood Service, Sydney, New South Wales, Australia, ${ }^{6}$ Faculty of Medicine, University of Sydney, Sydney, New South Wales, Australia, ${ }^{7}$ Dana-Farber Cancer Institute, Boston, MA, USA, ${ }^{8}$ Department of Neurology, Harvard Medical School, Boston, MA, USA, ${ }^{9}$ Westmead Millennium Institute, Westmead, New South Wales, Australia and ${ }^{10}$ National Serology Reference Laboratory, St. Vincent's Institute for Medical Research, Fitzroy, Victoria, Australia

Email: Lachlan Gray - lachlang@burnet.edu.au; Melissa J Churchill - churchil@burnet.edu.au; Jasminka Sterjovski - jasminka@burnet.edu.au; Kristie Witlox - kristiewitlox@hotmail.com; Jennifer C Learmont - JLearmont@arcbs.redcross.org.au;

John S Sullivan - JSullivan@arcbs.redcross.org.au; Steven L Wesselingh - stevew@burnet.edu.au;

Dana Gabuzda - dana_gabuzda@dfci.harvard.edu; Anthony L Cunningham - tony_cunningham@wmi.usyd.edu.au;

Dale A McPhee - dale@nrl.gov.au; Paul R Gorry* - gorry@burnet.edu.au

* Corresponding author

Published: 16 July 2007

Virology Journal 2007, 4:75 doi:10.1 186/1743-422X-4-75
Received: 6 July 2007

Accepted: 16 July 2007

This article is available from: http://www.virologyj.com/content/4/I/75

(c) 2007 Gray et al; licensee BioMed Central Ltd.

This is an Open Access article distributed under the terms of the Creative Commons Attribution License (http://creativecommons.org/licenses/by/2.0), which permits unrestricted use, distribution, and reproduction in any medium, provided the original work is properly cited.

\begin{abstract}
Background: The Sydney blood bank cohort (SBBC) of long-term survivors consists of multiple individuals infected with attenuated, nef-deleted variants of human immunodeficiency virus type I (HIV-I) acquired from a single source. Long-term prospective studies have demonstrated that the SBBC now comprises slow progressors (SP) as well as long-term nonprogressors (LTNP). Convergent evolution of nef sequences in SBBC SP and LTNP indicates the in vivo pathogenicity of HIV-I in SBBC members is dictated by factors other than nef. To better understand mechanisms underlying the pathogenicity of nef-deleted HIV-I, we examined the phenotype and env sequence diversity of sequentially isolated viruses $(n=2)$ from 3 SBBC members.

Results: The viruses characterized here were isolated from two SP spanning a three or six year period during progressive HIV-I infection (subjects D36 and C98, respectively) and from a LTNP spanning a two year period during asymptomatic, nonprogressive infection (subject $\mathrm{Cl}$ ). Both isolates from D36 were R5X4 phenotype and, compared to control HIV-I strains, replicated to low levels in peripheral blood mononuclear cells (PBMC). In contrast, both isolates from $\mathrm{C} 98$ and $\mathrm{Cl} 8$ were CCR5-restricted. Both viruses isolated from C98 replicated to barely detectable levels in PBMC, whereas both viruses isolated from $\mathrm{CI} 8$ replicated to low levels, similar to those isolated from D36. Analysis of env by VIV2 and V3 heteroduplex tracking assay, VIV2 length polymorphisms, sequencing and phylogenetic analysis showed distinct intra- and inter-patient env evolution.

Conclusion: Independent evolution of env despite convergent evolution of nef may contribute to the in vivo pathogenicity of nef-deleted HIV-I in SBBC members, which may not necessarily be associated with changes in replication capacity or viral coreceptor specificity.
\end{abstract}




\section{Background}

The Sydney blood bank cohort (SBBC) of long-term survivors (LTS) consists of multiple individuals who became infected with an attenuated strain of HIV-1 via contaminated blood products from a common blood donor between 1981 and 1984 [1-3]. Viral attenuation has been attributed to gross deletions in the nef and nef/long-terminal repeat (LTR) overlapping regions of the HIV-1 genome. Despite being infected from a single source, long-term prospective studies on SBBC members demonstrated that the cohort now consists of subjects with slow disease progression (SP), as well as individuals who remain true long-term nonprogressors (LTNP) and antiretroviral therapy-naive with stable CD4 counts and low or undetectable HIV-1 RNA levels [4]. Three SBBC members (one SP and two LTNP) have since died from causes unrelated to HIV-1 infection [3,4]. Although the cohort members had differing clinical courses, a comprehensive longitudinal analysis of nef/LTR sequences in the SBBC donor and four of the transfusion recipients demonstrated a convergent pattern of nef sequence evolution, characterized by progressive sequence deletions evolving toward a minimal nef/LTR structure that retains only the key sequence elements that are required for viral replication [4]. Thus, HIV-1 pathogenicity in SBBC members is dictated by viral and/or host determinants other than those that impose a unidirectional selection pressure on the nef/LTR region of the HIV-1 genome.

The HIV-1 env gene, which encodes the viral envelope glycoproteins (Env) is a significant viral determinant in HIV-1 pathogenesis [reviewed in [5-7]]. HIV-1 Env initiates viral entry via binding to CD4 and subsequently to a coreceptor, either CCR5 [8-12] or CXCR4 [13]. CCR5using (R5) HIV-1 strains predominate at early, asymptomatic stages of infection. In $40-50 \%$ of infected adults, progression of HIV-1 infection is accompanied by a switch in coreceptor specificity to HIV-1 variants able to use CXCR4 or both CCR5 and CXCR4 for entry (X4 or R5X4 strains, respectively) $[14,15]$. A switch in the specificity of HIV-1 Env from R5 to X4 or R5X4 is considered an indicator of poor prognosis, partly because it increases the number of CD4+ cells that are susceptible to cytolytic infection by HIV-1, and is associated with rapid progression of HIV-1 infection. R5 HIV-1 variants are present exclusively in the remaining $50-60 \%$ of infected individuals who progress to AIDS, without switching coreceptor specificity $[16,17]$, and exert pathogenic effects that contribute to HIV-1 progression via mechanisms that remain poorly understood [5]. Thus, changes in HIV-1 env that affect viral tropism are important for progression of HIV1 infection.

Analysis of inter- and intra-host evolution of env sequence has provided important insights relevant for HIV-1 trans- mission and progression. While several reports showed an inverse relationship between the rate and extent of viral diversification and progression of HIV-1 infection [1825 ], other studies demonstrated that disease progression is associated with increasing rates of viral diversity [2628]. A later study made significant headway in reconciling these conflicting studies by identifying 3 distinct phases of HIV-1 env sequence diversity and divergence during the asymptomatic period preceding the development of AIDS [29]; an early phase of variable duration with linear increases (approximately 1\% per year) in both viral divergence and diversity; an intermediate phase characterized by a continued increase in viral divergence but with a stabilisation or decline in viral diversity; and a late phase characterized by a stabilisation of viral divergence and a continued stability or decline in viral diversity. The emergence of X4 HIV-1 variants often coincided with transition between the early and intermediate phases. More recent studies identified convergent sequence evolution in env during the early phase toward a common ancestral sequence [30], suggesting that HIV-1 recovers certain ancestral features early in HIV-1 infection that most likely serve to restore viral fitness. However, other studies examining HIV-1 progression in individuals harbouring only R5 variants showed an increase in viral diversity in viral isolates obtained from patients with AIDS compared to isolates from asymptomatic individuals [31], raising the possibility that selection pressures driving HIV-1 evolution may be distinct in patients who maintain R5 viral variants compared to those who experience a coreceptor switch.

While the viral determinants underlying the pathogenicity of nef-deleted HIV-1 strains harbored by SBBC members are presently unknown, several lines of evidence support the hypothesis that evolution of HIV-1 env contributes to disease progression in this cohort; 1) compartmentalized evolution of HIV-1 V3 env sequence in cerebrospinal fluid (CSF) of the SBBC donor was shown to contribute to the development of HIV-associated dementia (HIVD) [32]; 2) enhanced cell killing in ex vivo human tissue cultures by HIV-1 isolates from the same SBBC subject was predicted to result from more efficient coreceptor usage [33]; and 3) increased Env-mediated fusion was shown to increase the in vivo pathogenicity of nef-deleted simian immunodeficiency virus (SIV) [34].

To better understand the role of HIV-1 env in the pathogenesis of nef-deleted HIV-1 strains harbored by SBBC members, we examined the phenotype and env sequence diversity of sequential viruses isolated from 3 SBBC members. Isolates from the SBBC "donor" (subject D36; SP) were R5X4 phenotype and replicated to low levels in peripheral blood mononuclear cells (PBMC). In contrast, isolates from 2 SBBC "recipients" (subjects C98 and C18; 
SP and LTNP, respectively) were CCR5-restricted with variable replication kinetics. Analysis of env by V1V2 and V3 heteroduplex tracking assay, V1V2 length polymorphisms, sequencing and phylogenetic analysis showed distinct intra- and inter-patient env evolution. Thus, independent evolution of env despite convergent evolution of nef may contribute to the in vivo pathogenicity of nefdeleted HIV-1 in SBBC members, which may not necessarily be associated with changes in replication capacity or viral coreceptor specificity.

\section{Results and discussion Subjects}

The clinical history of the study subjects, results of laboratory studies and antiretroviral therapies have been described in detail previously $[3,4,32]$. The results of laboratory studies relevant for the HIV-1 isolates used in this study are summarized in Table 1. Briefly, the SBBC donor, subject D36 presented with HIVD in December 1998 after being infected with HIV-1 for 18 years without antiretroviral therapy. The development of HIVD coincided with a fall in the CD4 cell count to $<200$ cells/ $\mu \mathrm{l}$ and the presence of high plasma and CSF HIV-1 RNA levels. The subject was placed on a highly active antiretroviral therapy (HAART) regimen of abacavir, nevirapine and zidovidine in January 1999, which suppressed plasma and CSF viral loads to below detectable levels and resolved the symptoms of HIVD $[32,35]$. As reported previously, transfusion recipient C98 commenced HAART in November 1999 after 16 years of HIV-1 infection, following a steady decline in CD4+ T-cells and a gradual increase in HIV-1 RNA from below detectable levels to 1500 RNA copies/ml $[3,4]$. He died in March 2002 of amyloidosis, which was not HIV-1 related. Likewise, transfusion recipient C18 died in 1995 of causes unrelated to HIV-1 infection. C18 remained antiretroviral therapy naive despite 12 years of infection, with stable CD4 cell counts and low plasma HIV-1 RNA levels [3]. Thus, subjects D36 and C98 showed evidence of slow progression while subject C18 remained a long-term nonprogressor.

HIV-1 isolated from PBMC on 2 consecutive occasions was used in this study (Table 1). The time between isolations ranged from 2 to 6 years. For the purpose of this report, the initial isolates are referred to as "early" isolates, and the subsequent isolates are referred to as "late" isolates (designated "E" and "L", respectively).

\section{Replication kinetics}

We first examined the capacity of the HIV-1 isolates to replicate in PHA-activated PBMC (Fig. 1). The R5 ADA and R5X4 89.6 HIV-1 strains were included as positive controls, and replicated rapidly to high levels peaking at day 7 post-infection (Fig. 1A). Both D36E and D36L viruses replicated to comparatively low levels, with similar kinetics as ADA and 89.6 (Fig. 1B). Both C18 viruses replicated with similar kinetics, but peak levels of replication by C18L were modestly higher (approximately 2 -fold) than those achieved by C18E (Fig. 1D). In contrast, replication of C98E and C98L viruses was barely detectable (Fig. 1C). Since D36 and C98 were slow progressors and C18 was a LTNP, there was no association between replication kinetics of HIV-1 isolates in PBMC and disease progression in the study subjects. However, the results highlight the heterogeneity in replication capacity by nef-deleted HIV-1 strains isolated from multiple subjects infected from a single source.

\section{Coreceptor usage}

The results of the preceding experiments suggest the existence of additional phenotypic changes that may contribute to altered replication capacity in PBMC. We therefore compared the coreceptor usage of HIV-1 isolates in Cf2Luc cells (Fig. 2). The R5 ADA and R5X4 89.6 strains were included as positive controls and used CCR5 or both CCR5 and CXCR4 for virus entry, respectively (Fig. 2A), as expected $[9,11,36]$. Consistent with results of previous

Table I: Subjects and laboratory studies

\begin{tabular}{|c|c|c|c|c|c|c|c|}
\hline Subject & Date of infection & $\begin{array}{l}\text { Date of blood } \\
\text { sample }\end{array}$ & Virus name & $\begin{array}{c}\text { CD4+ T-cell } \\
\text { count }(\text { cells } / \mu \mathrm{l})^{\mathrm{a}}\end{array}$ & $\begin{array}{c}\text { Viral load } \\
{\text { (RNA copies } / \mathrm{ml})^{\mathrm{b}}}\end{array}$ & Antiretroviral drugs ${ }^{c}$ & $\begin{array}{l}\text { Status of HIV-I } \\
\text { progression }^{d}\end{array}$ \\
\hline \multirow[t]{2}{*}{ D36 } & $01 / 1981$ & $07 / 1995$ & D36E & 552 & 1500 & ABC, AZT, NVP (I/I999-9/2004) & $\mathrm{SP}$ \\
\hline & & $01 / 1999$ & D36L & 160 & 9900 & ABC, NVP, 3TC (9/2004-present) & \\
\hline \multirow[t]{2}{*}{$\mathrm{Cl} 8$} & $08 / 1983$ & $01 / 1992$ & $\mathrm{CI} 8 \mathrm{E}$ & 690 & N/A & None & LTNP \\
\hline & & $03 / 1994$ & $\mathrm{CI} 8 \mathrm{~L}$ & 809 & 2805 & & \\
\hline \multirow[t]{2}{*}{$\mathrm{C} 98$} & $01 / 1982$ & $07 / 1993$ & C98E & 880 & N/A & d4T, NVP, IND ( I I/I 999-death) & $\mathrm{SP}$ \\
\hline & & $11 / 1999$ & C98L & 585 & $\mathrm{BD}$ & & \\
\hline
\end{tabular}

aCD4+ T-cell levels were measured by flow cytometry.

bPlasma HIV-I RNA was measured using COBAS AMPLICOR monitor version I.0 (Roche Molecular Diagnostic Systems, Branchburg, N.J.) prior to July 1999 and version I.5 after July 1999. HIV-I RNA levels of $<400$ copies/ml (version I.0) or $<50$ copies/ml (version I.5) were considered below detection. BD, below detection; N/A, not available.

cABC, abacavir; AZT, zidovudine; NVP, nevirapine; 3TC, lamivudine; d4T, stavudine; IND, indinavir.

dSP, slow progressor; LTNP, long-term nonprogressor. Comprehensive laboratory data collected since 1993 and detailed clinical history of the study subjects has been published previously [3, 4, 32], which was used to classify subjects as SP or LTNP. 
(A) Control viruses

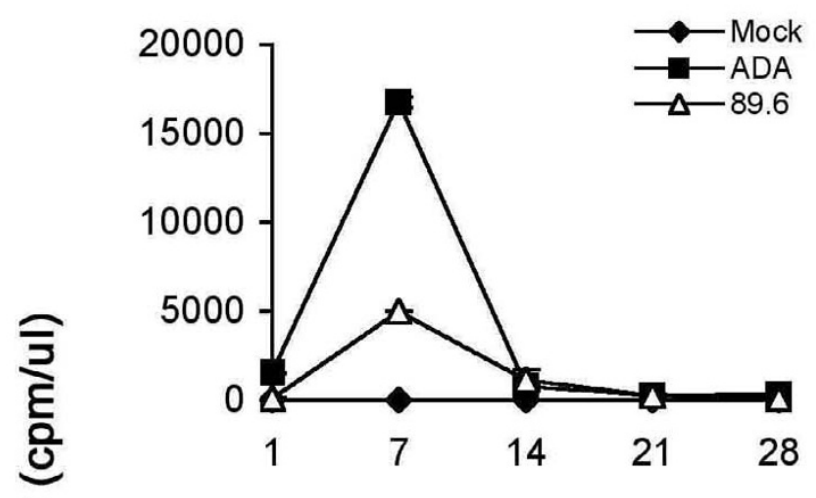

(C) C98 viruses

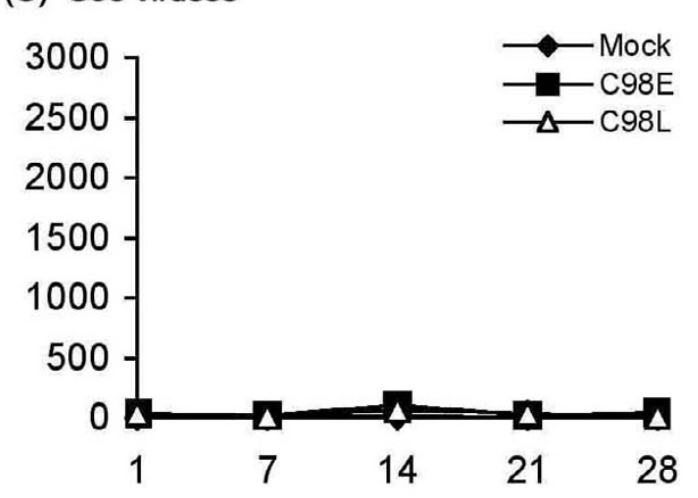

(B) D36 viruses

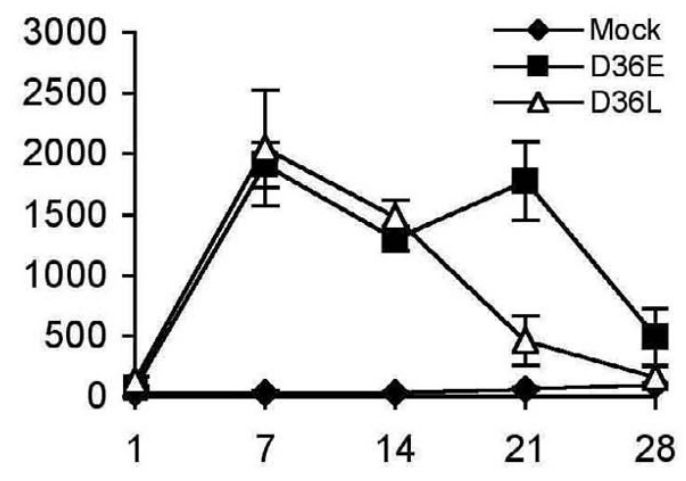

(D) C18 viruses

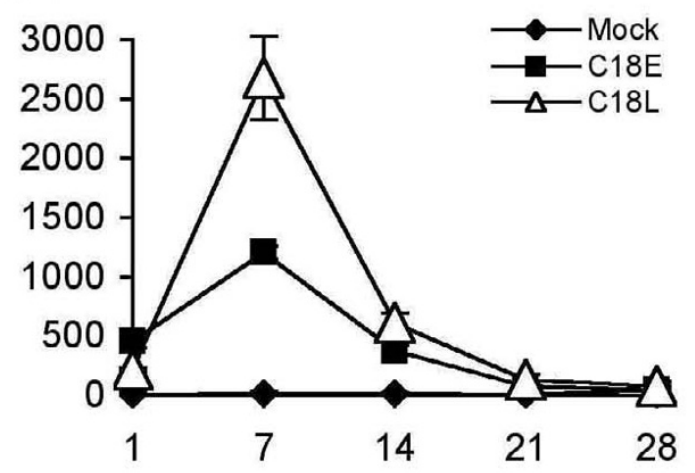

Days post-infection

Figure I

Replication kinetics in PBMC. PBMC were infected with equivalent amounts of each virus, as described in the Methods, and cultured for 28 days. Virus production in culture supernatants was measured by RT assays. Values shown are means from duplicate infections. Error bars represent standard deviations. Results are representative of two independent experiments using cells obtained from different donors.

studies [32], D36E and D36L viruses were dual tropic and used CCR5 and CXCR4 for virus entry (Fig. 2B). C98E, C98L, C18E and C18L viruses used CCR5 only for virus entry. Replication of dual tropic D36E and D36L viruses in PBMC was abolished by preincubation of cells with the CXCR4 inhibitor AMD3100 [37,38], but was unaffected by the CCR5 inhibitor TAK-779 [39] (data not shown). This suggests that the viral quasispecies in D36 isolates are not a mixture containing R5 variants, and confirms previous studies that showed infection of PBMC by R5X4 viruses occurs primarily via CXCR4 [40]. Thus, D36 isolates are of R5X4 phenotype, and C18 and C98 isolates are of R5 phenotype. These results indicate that the presence of a functional nef gene is not required for HIV-1 to undergo a switch in coreceptor preference from R5 to R5X4. However, since D36 harbored R5X4 variants with- out antiretroviral therapy while remaining asymptomatic for at least 4 years (Table 1), the results suggest that acquisition of an R5X4 phenotype is not sufficient for rapid disease progression in the absence of nef. Moreover, the fact that C98 maintained an R5 virus that replicated poorly in PBMC, despite evidence of disease progression, suggests that nef-deleted viruses may acquire increased pathogenicity in vivo by mechanism(s) that are not necessarily associated with changes in coreceptor usage or enhanced replicative capacity in vitro.

\section{VIV2 and V3 HTA analysis}

Changes in the dominant viral quasispecies may serve to augment HIV-1 pathogenicity in vivo without increasing replication capacity or changing coreceptor preference in vitro [5]. Therefore, to determine whether distinct viral 
(A) Control viruses

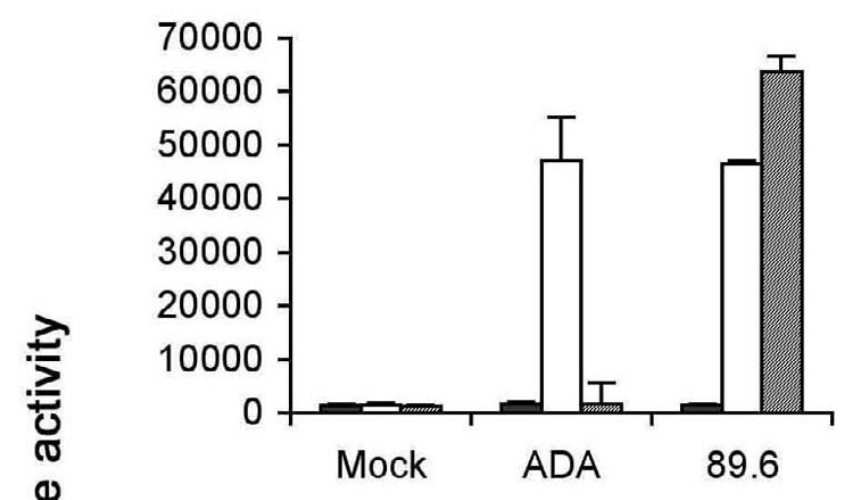

(C) C98 viruses

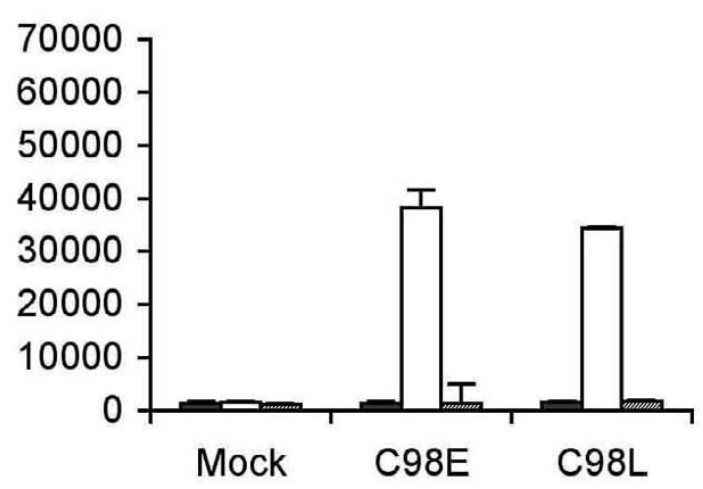

(B) D36 viruses

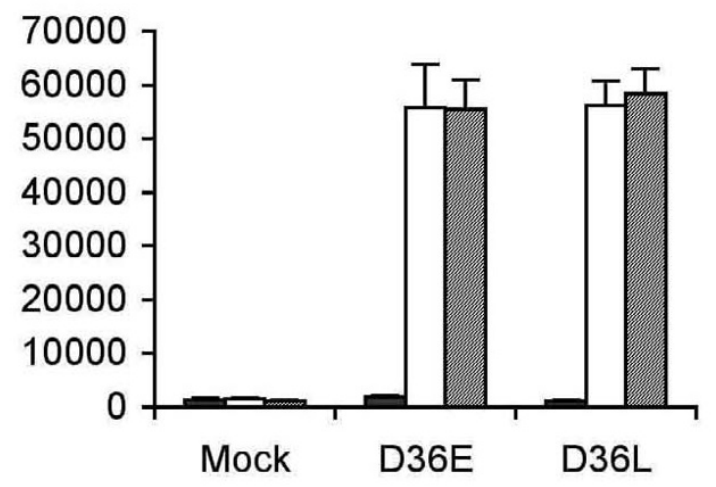

(D) C18 viruses

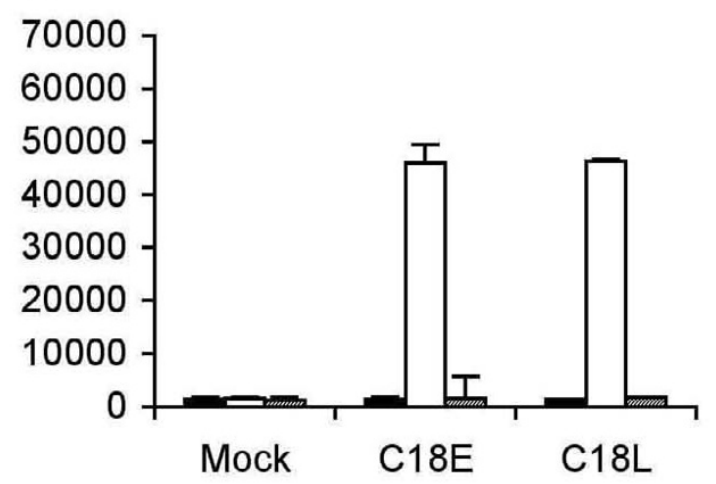

\section{$\square$ CD4 only $\square$ CD4+CCR5 $\square$ CD4+CXCR4}

\section{Figure 2}

Coreceptor usage by primary HIV-I isolates. Cf2-Luc cells were transfected with pcDNA3-CD4 alone or cotransfected with pcDNA3-CD4 and pcDNA3 expressing CCR5 or CXCR4 and infected with equivalent amounts of each HIV-I isolate as described in the Methods. Cell lysates were prepared at $48 \mathrm{~h}$ post-infection and assayed for luciferase activity. Data are expressed as means from duplicate infections. Error bars represent standard deviations. Similar results were obtained in three independent experiments.

variants are present in early and late D36, C18 and C98 viruses, Env V1V2 and V3 HTA analyses were conducted.

The V1V2 and V3 HTAs were conducted using [ $\left.{ }^{32} \mathrm{P}\right]-$ labelled probes generated from the R5 ADA Env or the X4 NL4-3 Env (Figs. 3 and 4; left and right panels, respectively). HTA negative controls consisted of reactions containing probe alone or mixed with homologous, unlabelled target DNA to identify homoduplexes. HTA positive controls consisted of ADA probe in reactions containing unlabelled NL4-3 or 89.6 Env (Figs. 3 and 4; left panels), or NL4-3 probe in reactions containing unla- belled ADA or 89.6 Env (Fig. 3 and 4, right panels) to identify heteroduplexes. V1V2 HTAs using either probe demonstrated that C98L contained 2 dominant variants that were distinct from the single, dominant species found in C98E (Fig. 3). Similarly, V1V2 HTAs with either probe demonstrated 2 dominant variants in D36L that were distinct from 4 variants found in D36E. V1V2 HTAs using the NL4-3 probe demonstrated 3 variants in C18L that were distinct from 4 variants found in C18E. However, the ADA probe appeared to be less sensitive for detecting distinct V1V2 variants in $\mathrm{C} 18 \mathrm{E}$ and $\mathrm{C} 18 \mathrm{~L}$ viruses. In addition to the presence of distinct V1V2 heteroduplexes between 
viruses isolated from individuals, V1V2 heteroduplexes were also distinct between subjects.

The V3 heteroduplex patterns also demonstrated distinct viral variants using either probe (Fig. 4). However, the resolution of V3 heteroduplexes was more readily achieved using the NL4-3 probe. V3 HTAs demonstrated 4 major variants in $\mathrm{C} 18 \mathrm{~L}$ that were distinct from a single variant present in $\mathrm{C} 18 \mathrm{E}$; 2 major variants in C98L that were distinct from a single major variant present in C98E; and 2 major variants in D36L that were distinct from 2 major variants present in D36E. Similar to results of the V1V2 HTAs (Fig. 3), the V3 heteroduplexes also appeared to be distinct between subjects. Together, the results of the V1V2 and V3 HTAs suggest significant inter- and intrapatient evolution of HIV-1 Env. In contrast to convergent sequence evolution previously reported for HIV-1 nef in the study subjects [4], the V1V2 and V3 HTA results suggest independent evolution of HIV-1 Env.

\section{VIV2 length polymorphism analysis}

The V1V2 region of HIV-1 Env contains extensive length polymorphisms, which can be utilized to compare the genetic relationships between different viral populations [41]. Furthermore, V2 region extensions have been associated with slow progression or long-term nonprogression of HIV-1 infection [23,42]. We further investigated the extent of HIV-1 Env diversity in SBBC viral isolates by measuring V1V2 length polymorphisms using GeneScan assay (Fig. 5). Although GeneScan analysis is unable to discriminate between distinct V1V2 variants of the same length which contain discrete amino acid substitutions, it has the sensitivity to detect a single nucleotide (nt) deletion or insertion within PCR products [41]. D36E virus contained 2 dominant V1V2 length polymorphisms
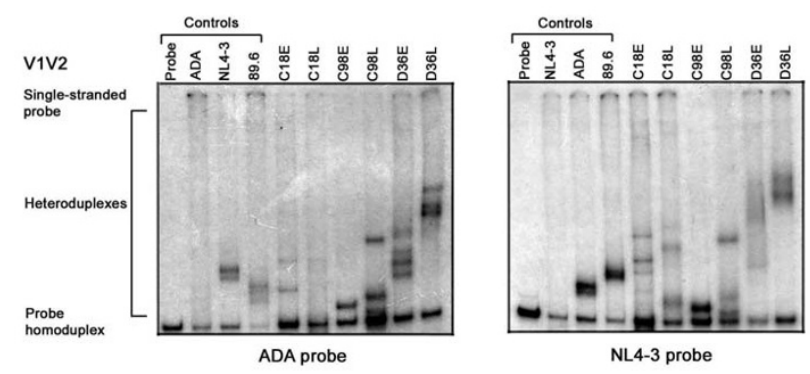

\section{Figure 3}

VIV2 HTA analysis. HIV-I Env VIV2 regions were amplified by PCR from genomic DNA of HIV-I infected PBMC and subjected to HTA analysis as described in the Methods. HTA analysis using a [32P]-labelled ADA VIV2 Env probe is shown in the left panel, and HTA analysis using a [ $\left.{ }^{32} \mathrm{P}\right]$-labelled NL43 VIV2 Env probe is shown in the right panel. Similar results were obtained in three independent experiments.
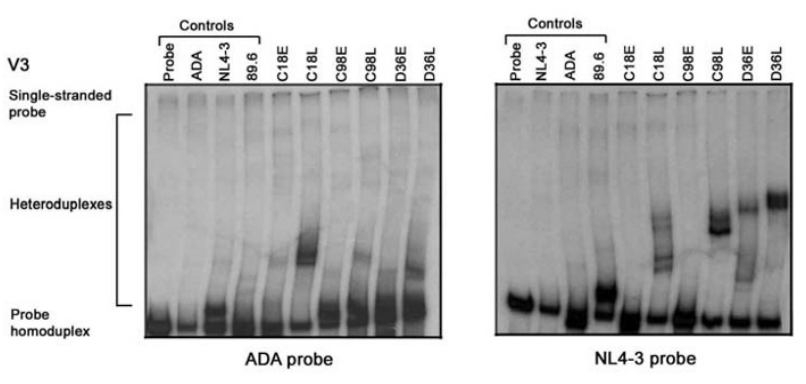

\section{Figure 4}

V3 HTA analysis. The HIV-I Env V3 region was amplified by PCR from genomic DNA of HIV-I infected PBMC and subjected to HTA analysis as described in the Methods. HTA analysis using a [ $\left.{ }^{32} \mathrm{P}\right]$-labelled ADA V3 Env probe is shown in the left panel, and HTA analysis using a [32P]-labelled NL4-3 V3 Env probe is shown in the right panel. Similar results were obtained in three independent experiments.

measuring 271 and $277 \mathrm{nt}$, whereas D36L virus contained one dominant species measuring $280 \mathrm{nt}$ and 4 minor species measuring 255, 268, 269 and 277 nt (Fig. 5). C98E and C98L viruses each contained single, dominant V1V2 length polymorphisms measuring 241 and $267 \mathrm{nt}$, respectively. C18E virus contained a single, dominant V1V2 length polymorphism measuring $241 \mathrm{nt}$, which was identical in nt length to the dominant species detected in C98E virus. However, C18L contained 5 distinct V1V2 length polymorphisms measuring 240,247,249, 250 and 252 nt. Thus, in each study subject, late viruses contained variants with V1V2 nt lengths that were distinct from those detected in early viruses.

These results suggest that significant evolution of V1V2 Env occurred in each of the study subjects, an interpretation supported also by results of the V1V2 HTA analysis (Fig. 3). That $\mathrm{C} 18 \mathrm{E}$ and $\mathrm{C} 98 \mathrm{E}$ viruses contained dominant variants with identical V1V2 nt length raises the possibility that these 2 subjects once harboured Env variants with some shared features. However, the increase in number of V1V2 length polymorphisms in D36L and C18L viruses compared to $\mathrm{D} 36 \mathrm{E}$ and $\mathrm{C} 18 \mathrm{E}$ viruses, respectively, the shift in dominant V1V2 length polymorphism in C98 viruses, and the lack of overlap between V1V2 length variants detected in D36L, C98L and C18L viruses suggests divergent evolution of HIV-1 Env in these SBBC study subjects. In contrast to previous studies [23,42], long-term survival of HIV-1 infection in these subjects was not associated with increased V1V2 nt length. Furthermore, significant increases in V1V2 nt length diversity were observed in late viruses from a SP (D36) and a LTNP (C18) compared to respective early viruses, and no increase in V1V2 nt length diversity was observed in late virus from a SP (C98); this suggests that divergent evolution of HIV-1 Env 

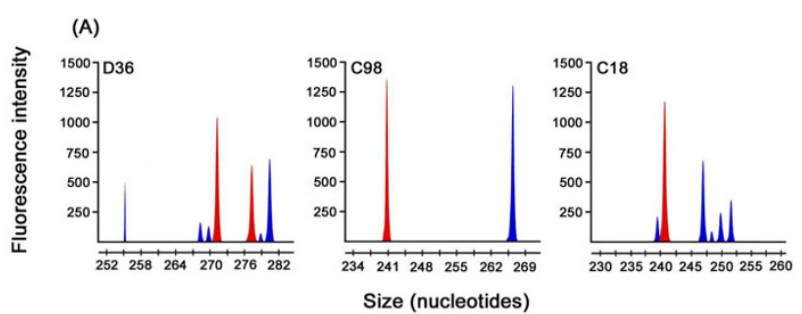

(B)
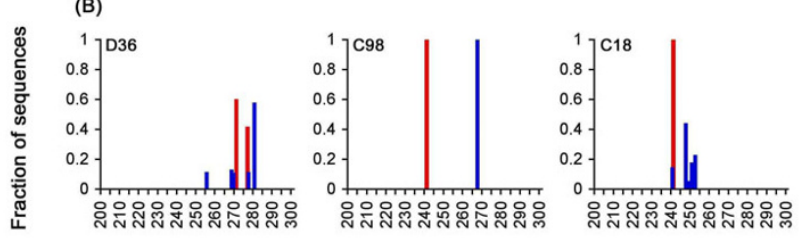

V1V2 length (nucleotides)

\section{Figure 5}

VIV2 length polymorphism analysis. The HIV-I Env VIV2 region incorporating a 6-carboxy-fluorescien fluorophore was amplified by PCR from genomic DNA of HIV-I infected PBMC and subjected to GeneScan analysis, as described in the Methods and elsewhere [4I, 56]. (A) GeneScan sample files generated from amplified products. (B) Fraction of sequences with a given VIV2 nucleotide length, which was calculated from GeneScan sample files. Peaks and bars shown in red represent VIV2 amplimers from early viruses, and peaks and bars shown in blue represent VIV2 amplimers from late viruses. Similar results were obtained in two independent experiments.

in the study subjects was neither necessary nor sufficient for disease progression.

\section{Sequence analysis}

The preceding studies showed differences in phenotype between D36, C98 and C18 viruses and evidence of divergent Env sequence evolution. However, an association between disease progression and results of phenotypic or genetic studies could not be made. To determine the genetic basis underlying differences in viral phenotype, and to better understand Env sequence changes which may contribute to HIV-1 progression in SBBC members, the gp120 region of Env was cloned and the V1 to V3 region of multiple, independent Envs sequenced. Phylogenetic analysis of interpatient sequence sets showed monophyletic clustering of D36 Env sequences (Fig. 6). The majority of C98 and C18 Env sequences clustered separately, but 1 C18 Env (C18L.3) clustered with C98 Envs, suggesting the presence of shared sequence similarities. This is not unexpected, since C18 and C98 were infected with a closely related HIV-1 strain and, unlike D36 whose virus had a coreceptor switch (Fig. 2), both C18 and C98 continued to harbor less evolved R5 variants. Analysis of intrapatient sequence sets showed that the majority of

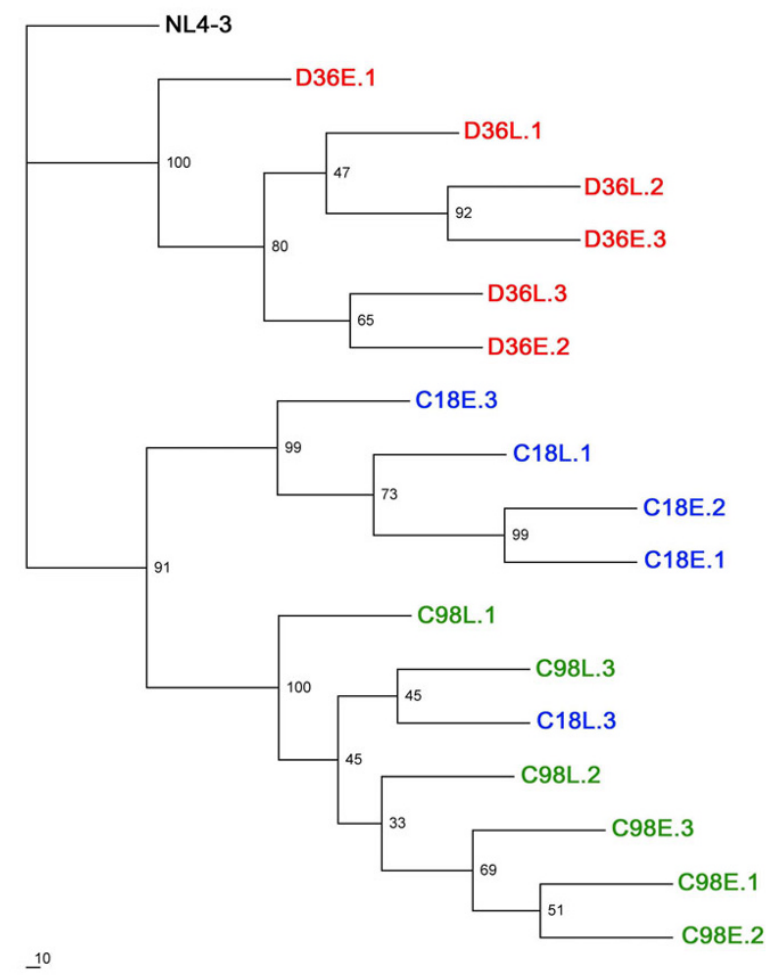

Figure 6

Phylogenetic analysis. Env nucleotide sequences were subjected to maximum likelihood analysis as described in the Methods. Branches labelled in green, blue and red represent sequences cloned from subjects $C 98, C 18$ and D36, respectively. $\mathrm{E}$, clones from early viruses; $\mathrm{L}$, clones from late viruses.

C18E and C98E clones cosegregated separately from C18L and C98L clones, respectively. However, clear cosegregation of D36E and D36L Envs in the monophyletic D36 cluster was not evident. Since phylogenetic analysis ignores sequence insertions and deletions, this suggests that Env sequence evolution in D36 may primarily involve nucleotide insertions and/or deletions rather than discrete substitutions.

Multiple sequence alignments of the V1V2 and V3 regions of Envs cloned from each virus are shown in Fig. 7A and $7 \mathrm{~B}$, respectively. The net charge of the $\mathrm{V} 3$ regions of $\mathrm{D} 36 \mathrm{E}$ and $\mathrm{D} 36 \mathrm{~L}$ clones was +6 , and the net charge of the $\mathrm{V} 3$ regions of $\mathrm{C} 98 \mathrm{E}, \mathrm{C} 98 \mathrm{~L}, \mathrm{C} 18 \mathrm{E}$ and $\mathrm{C} 18 \mathrm{~L}$ clones was +2 or +3 . Consistent with results obtained in coreceptor usage assays with HIV-1 isolates (Fig. 2), coreceptor usage based on net V3 charge using the sinsi matrix [43] predicts D36E and D36L clones to be R5X4 phenotype, and C98E, C98L, $\mathrm{C} 18 \mathrm{E}$ and $\mathrm{C} 18 \mathrm{~L}$ clones to be R5 phenotype. Although the presence of a basic residue at position 11 or 25 in $\mathrm{V} 3$ is 
strongly associated with CXCR4 usage $[44,45]$, all D36E and D36L clones lacked basic residues at either position. Therefore, although D36E and D36L viruses are R5X4 phenotype in transfected Cf2th cells and use CXCR4 for HIV-1 entry into PBMC (data not shown), CXCR4 use for HIV-1 entry was not determined by the presence of charged amino acids at positions 11 or 25 . Recently, the presence of isoleucine at amino acid 326 in V3, or proline or cysteine residues in V1 was shown to be important for macrophage (M) tropism of the R5X4 HIV-1 89.6 strain and other blood-derived, M-tropic R5X4 viruses [46]. In support of these results, D36E and D36L Envs lack these genetic changes, and the primary isolates replicate poorly in cultures of monocyte-derived macrophages (MDM) compared to 89.6 [47].

The base of the V1V2 stem contains a highly conserved potential N-linked glycosylation site in the CNTS sequence of NL4-3 (Fig. 7A), which is present in all but seven of 208 clade B HIV-1 Env sequences screened from the Los Alamos National Laboratory HIV Database [48].
One of 3 D36E clones and 2/3 D36L clones lacked a potential N-linked glycosylation site at this position (Fig. 7A). Similarly, the glycosylation site at this position was lacking in $1 / 3 \mathrm{C} 98 \mathrm{E}$ and $1 / 3 \mathrm{C} 98 \mathrm{~L}$ clones. In contrast, the glycosylation site at the V1V2 stem was conserved among all C18E and C18L clones, and in contrast to D36 and C98 clones there was a high degree of sequence homology in this region to that of NL4-3. Elimination of a glycosylation site at this position is sufficient for CD4-independent infection by HIV-1 ADA, achieved by altering the position of the V1V2 loops and exposing the coreceptor binding site in gp120 [49-52]. Thus, alterations in glycosylation at the V1V2 stem may serve to enhance receptor binding, which could contribute to HIV-1 pathogenicity at later stages of HIV-1 infection. To this end, it is interesting to note that Env clones lacking this glycosylation site were present only in SBBC slow progressors (D36 and C98), whereas the glycosylation site was present in all Envs from the LTNP (C18). Further sequence analysis of a greater number of Env clones is required to determine the significance of this sequence change in SBBC SPs and LTNPs. In

\section{(A)

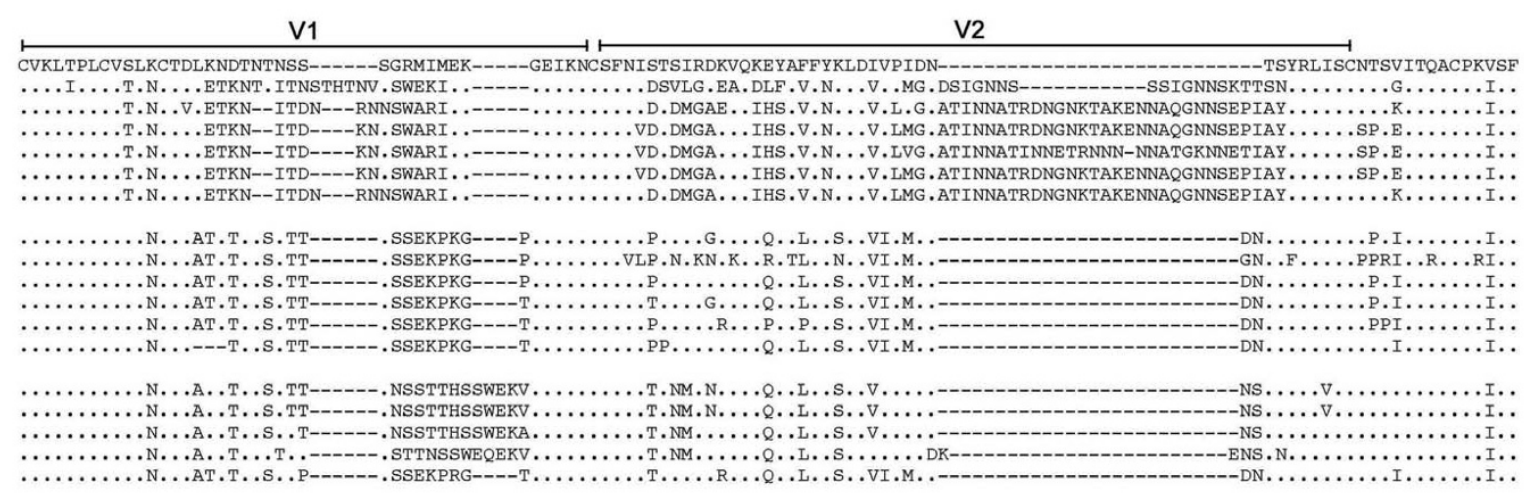

(B)

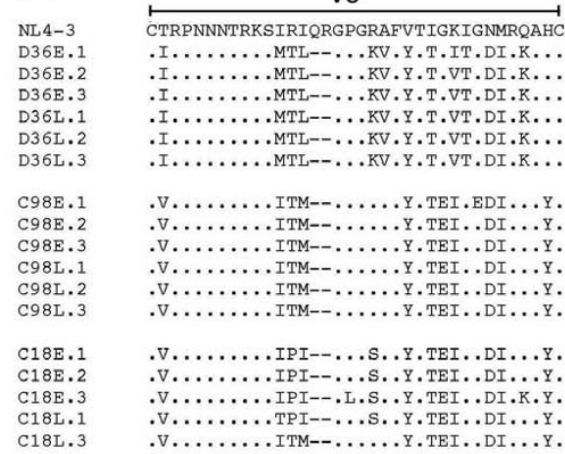

\section{Figure 7}

Env VIV2 and V3 amino acid sequences. HIV-I Env amino acid sequences spanning the VIV2 (A) or V3 (B) regions of Env genes cloned into pGEM-T-easy were obtained as described in the Methods. Amino acid alignments are compared to Env from HIV-I NL4-3. Dots indicate residues identical to NL4-3, and dashes indicate gaps. 
addition, further studies to biologically characterize these Envs are required to determine whether SBBC Envs exhibit functional changes that could potentially contribute to HIV-1 pathogenicity.

\section{Conclusion}

In this study, we analyzed the phenotype and Env sequences of HIV-1 present in 3 SBBC members who were slow progressors or long-term nonprogressors. Early and late viruses from D36 were R5X4 whereas viruses isolated from C98 and C18 remained CCR5-restricted, indicating that a coreceptor switch was neither necessary nor sufficient for disease progression in these subjects. Replication capacity of these viruses in PBMC ranged from rapid to barely detectable and was not associated with disease progression. Although SBBC subjects had evidence of convergent evolution of nef sequence [4], analysis of Env diversity by V1V2 and V3 HTA, V1V2 length polymorphism assay, and maximum likelihood phylogeny suggest that Env sequence evolution was divergent in SP and LTNP subjects. Our results suggest that evolution toward a pathogenic Env phenotype may occur in long-term survivors infected with nef-deleted HIV-1, which is not necessarily associated with changes in replication capacity or coreceptor usage, or degree of Env sequence diversity.

\section{Methods \\ Isolation of HIV-I}

HIV-1 was isolated from patient's PBMC by coculture with selected PBMC according to published methods [36]. Briefly, $2 \times 10^{6}$ patient PBMC were mixed with $10 \times 10^{6}$ PHA-activated PBMC from 2 normal uninfected donors, and cocultured for 28 days in RPMI-1640 medium containing $10 \%$ (vol/vol) fetal calf serum (FCS) and $20 \mathrm{U} / \mathrm{ml}$ interleukin-2 (IL-2). Fifty percent media changes were performed twice weekly. Five million PHA-activated PBMC from a different donor were added at every second media change. Supernatants were tested for reverse transcriptase (RT) activity using [ $\left.{ }^{33} \mathrm{P}\right] \mathrm{dTTP}$ incorporation as described previously [53]. Supernatants testing positive for RT activity were filtered through $0.45 \mu \mathrm{m}$ filters and stored at $80^{\circ} \mathrm{C}$.

\section{HIV-I replication kinetics}

Five hundred thousand PHA-activated PBMC were infected in 48 -well tissue culture plates by incubation with $1 \times 10^{6}[33 \mathrm{P}] \mathrm{cpm}$ RT units of virus supernatant in a volume of $250 \mu \mathrm{l}$ for $3 \mathrm{~h}$ at $37^{\circ} \mathrm{C}$, as described previously $[32,54]$. Virus was then removed, and PBMC were washed 3 times with phosphate-buffered saline (PBS) and cultured in RPMI-1640 medium containing $10 \%$ (vol/vol) FCS and $20 \mathrm{U} / \mathrm{ml} \mathrm{IL-2} \mathrm{for} 27$ days. Fifty percent medium changes were performed twice weekly, and supernatants were tested for HIV-1 replication by RT assays on days 1 , $7,14,21$ and 28 post-infection.

\section{Coreceptor usage}

Coreceptor usage by primary HIV-1 isolates was determined using Cf2-Luc cells expressing CD4 alone, or expressing CD4 together with CCR5 or CXCR4, as described previously $[32,36,54,55]$. Briefly, Cf2-Luc cells were transfected with $10 \mu \mathrm{g}$ of plasmid pcDNA3-CD4 and $20 \mu \mathrm{g}$ of plasmid pcDNA3 containing CCR5 or CXCR4 using the calcium phosphate method, and infected $48 \mathrm{~h}$ later by incubation with $1 \times 10^{6}\left[{ }^{33} \mathrm{P}\right] \mathrm{cpm}$ RT units of HIV1 in the presence of $2 \mu \mathrm{g}$ of Polybrene (Sigma) per ml. After overnight infection, virus was removed and the cells were cultured for an additional $48 \mathrm{~h}$ prior to lysis in 200 $\mu \mathrm{l}$ of cell lysis buffer (Promega, Madison, Wis.). Cell lysates were cleared by centrifugation, and assayed for luciferase activity (Promega) according to the manufacturer's protocol.

\section{VIV2 and V3 HTA}

The V1V2 probes were generated by PCR amplification of a 282 bp fragment of the HIV-1 ADA or NL4-3 Env using primers SK122 (5'-CAAGCCTAAAGCCATGTGTA-3'; corresponding to nucleotide positions 6561 to 6580 of NL43) and SK123 (5'-TAATGTATGGGAATTGGCTCAA-3'; corresponding to nucleotide positions 6822 to 6843 of NL43 ). The V3 probes were generated by PCR amplification of a 239 bp fragment of the HIV-1 ADA or NL4-3 Env using primers V3c (5'-CCATAATAGTACAGCTGAATG-3'; corresponding to nucleotide positions 7062 to 7081 of NL4-3) and V3d (5'-ATTTCTGGGTCCCCTCCTGAGGATTG-3'; corresponding to nucleotide positions 7276 to 7301 of NL4-3). Labelling was achieved by incorporation of $\alpha$ [32P]-dCTP in the PCR, which consisted of an initial denaturation at $95^{\circ} \mathrm{C}$ for $5 \mathrm{~min}$, followed by 25 cycles of $95^{\circ} \mathrm{C}$ for $30 \mathrm{sec}, 52^{\circ} \mathrm{C}$ for $1 \mathrm{~min}$, and $72^{\circ} \mathrm{C}$ for $2 \mathrm{~min}$ followed by a final extension step of $72^{\circ} \mathrm{C}$ for $7 \mathrm{~min}$. Unincorporated nucleotides were removed using a QIAquick spin column (Qiagen). The V1V2 and V3 Env target DNA sequences were generated from genomic DNA of PBMC infected with each primary HIV-1 isolate by PCR using primers SK122/SK123 and V3c/V3d, respectively. Genomic DNA of PBMC infected with HIV-1 ADA, NL4-3 or 89.6 was used as controls. PCR reactions proceeded as described above, except that radiolabelled dCTP was not included. Amplimers were purified using a QIAquick spin column (Qiagen). Heteroduplex reactions were performed as described previously [21] with the following modifications. The reactions consisted of $1 \times$ annealing buffer [1 M NaCl, $100 \mathrm{mM}$ Tris-HCL (pH 7.5), $20 \mathrm{mM}$ EDTA], $5 \mu \mathrm{l}$ unlabelled V1V2 or V3 target PCR product, and $2.5 \mu$ labelled V1V2 or V3 probe. The reactions were denatured at $95^{\circ} \mathrm{C}$ for $4 \mathrm{~min}$ and then allowed to anneal on wet ice for $5 \mathrm{~min}$. The heteroduplexes were separated in $5.5 \%$ (wt/vol) polyacrylamide gels in $1 \times$ Tris-borateEDTA buffer, and were visualized by autoradiography of dried HTA gels. 


\section{VIV2 length polymorphism analysis}

V1V2 length polymorphisms in HIV-1 Env were quantified using a fluorescent-based assay that has been described in detail previously [41]. This technique measures HIV-1 sequence diversity by taking advantage of frequent length polymorphisms that occur within the V1V2 region of HIV-1 Env, and has the sensitivity to detect a single nucleotide deletion or insertion. Briefly, the V1V2 region of HIV-1 Env was amplified from genomic DNA of PBMC infected with each primary HIV-1 isolate by nested PCR using outer primers V12-51 and V12-52, and inner primers V12-50 and V12-53, as described previously [41]. The V12-50 primer used in the second round PCR was labelled with a fluorophore, 6-carboxy-fluorescien, at the 5' end (PE Biosystems). PCR amplified, fluorescently labelled products were purified using QIAquick spin columns (Qiagen), separated in 6\% (wt/vol) denaturing polyacrylamide gels using an automated sequencer (ABI PRISM 377; PE Biosystems) and analysed using GeneScan software (PE Biosystems). Peaks with areas $<10 \%$ of the total peak area were considered not significant, as described previously [56]. The fraction of sequences in the viral quasispecies with a given nucleotide length was calculated from GeneScan data and plotted against nucleotide length, as described previously [57].

\section{Env cloning, sequencing and phylogenetic analysis}

A $2.1 \mathrm{~kb}$ fragment of HIV-1 Env (corresponding to nucleotide positions 6332 to 8452 in NL4-3) was amplified from genomic DNA of PBMC infected with each primary HIV-1 isolate by nested PCR using outer primers env1A and $e n v 1 \mathrm{M}$ [58], and inner primers envKpnI and envBamHI [59], as described previously [60], and cloned into pGEMT Easy (Promega). The V1 to V3 region of 2 to 3 independent Envs cloned from each primary HIV-1 isolate was sequenced using a SequiTherm EXCEL II DNA sequencing kit (Epicenter Technologies, Madison, WI) and a model 4000L LI-COR DNA sequencer (LI-COR, Lincoln, NE). Nucleotide sequences were aligned using CLUSTALW and corrected by hand. Phylogeny was estimated by a maximum likelihood algorithm (DNAml) with a transition/ transversion ratio of 2.0, empirical base frequencies, and a randomised input order of sequences. Bootstrap values were calculated from 100 resamplings of the same alignment using Seqboot.

\section{Nucleotide sequence accession numbers}

The V1 to V3 Env nucleotide sequences reported here have been assigned GenBank accession numbers DQ665223 to DQ665240.

\section{Competing interests}

The author(s) declare that they have no competing interests.

\section{Authors' contributions}

LG carried out the virus replication studies, DNA sequencing and sequence analysis, and the GeneScan analyses; JS, MJC and KW carried out the HTA studies; ALC assisted with the HTA studies; MJC and JS assisted with the DNA sequencing; DAM carried out the HIV-1 virus isolations; JCL and JSS provided patient samples and clinical data; MJC, SLW, DG, ALC and DAM contributed to the study design, assisted with manuscript preparation, and helped edit the manuscript; DG undertook HIV-1 coreceptor testing in conjunction with PRG; MJC, SLW, DG, ALC, DAM and PRG analyzed and interpreted the data; PRG designed and oversaw the study, and wrote the manuscript. All authors read and approved the manuscript.

\section{Acknowledgements}

We thank J. Sodroski and B. Etemad-Moghadam for providing Cf2-Luc cells, and J. Sodroski for providing CD4 and coreceptor plasmids. This study was supported, in part, by a grant from the National Health and Medical Research Council of Australia (NHMRC) to PRG (25I520), a grant from the American Foundation for AIDS Research (amfAR) to DAM (106669), and grants from the National Institutes of Health to PRG (Al054207) and DG (NS37277). LG and JS are recipients of NHMRC Dora Lush Biomedical Research Scholarships. PRG is the recipient of an NHMRC R. Douglas Wright Biomedical Career Development Award.

\section{References}

I. Deacon NJ, Tsykin A, Solomon A, Smith K, Ludford-Menting M, Hooker DJ, McPhee DA, Greenway AL, Ellett A, Chatfield C, et al:: Genomic structure of an attenuated quasi species of HIV-I from a blood transfusion donor and recipients. Science 1995, 270(5238):988-99|.

2. Learmont J, Tindall B, Evans L, Cunningham A, Cunningham P, Wells J. Penny R, Kaldor J, Cooper DA: Long-term symptomless HIV$I$ infection in recipients of blood products from a single donor. Lancet 1992, 340(8824):863-867.

3. Learmont JC, Geczy AF, Mills J, Ashton LJ, Raynes-Greenow CH, Garsia RJ, Dyer WB, Mclntyre L, Oelrichs RB, Rhodes DI, Deacon NJ, Sullivan JS: Immunologic and virologic status after I 4 to I 8 years of infection with an attenuated strain of HIV-I. A report from the Sydney Blood Bank Cohort. N Engl J Med 1999, 340(22): $1715-1722$.

4. Churchill MJ, Rhodes DI, Learmont JC, Sullivan JS, Wesselingh SL, Cooke IR, Deacon NJ, Gorry PR: Longitudinal analysis of human immunodeficiency virus type I nef/long terminal repeat sequences in a cohort of long-term survivors infected from a single source. J Virol 2006, 80(2): 1047-1052.

5. Gorry PR, Churchill M, Crowe SM, Cunningham AL, Gabuzda D: Pathogenesis of macrophage tropic HIV. Curr HIV Res 2005, 3(I):53-60.

6. Berger EA, Murphy PM, Farber JM: Chemokine receptors as HIVI coreceptors: roles in viral entry, tropism, and disease. Annu Rev Immunol 1999, 1 7:657-700.

7. Doms RW, Trono D: The plasma membrane as a combat zone in the HIV battlefield. Genes Dev 2000, I 4(2I):2677-2688.

8. Alkhatib G, Combadiere C, Broder CC, Feng Y, Kennedy PE, Murphy PM, Berger EA: CC CKR5: a RANTES, MIP-I alpha, MIP-I beta receptor as a fusion cofactor for macrophage-tropic HIV-I. Science 1996, 272(5270): 1955-1958.

9. Choe H, Farzan M, Sun Y, Sullivan N, Rollins B, Ponath PD, Wu L, Mackay CR, LaRosa G, Newman W, Gerard N, Gerard C, Sodroski J: The beta-chemokine receptors CCR3 and CCR5 facilitate infection by primary HIV-I isolates. Cell 1996, 85(7): | | 35-|| 48.

10. Deng H, Liu R, Ellmeier W, Choe S, Unutmaz D, Burkhart M, Di Marzio P, Marmon S, Sutton RE, Hill CM, Davis CB, Peiper SC, Schall TJ, Littman DR, Landau NR: Identification of a major co-receptor for primary isolates of HIV-I. Nature 1996, 38 I (6584):66 I-666. 
II. Doranz B], Rucker J, Yi Y, Smyth RJ, Samson M, Peiper SC, Parmentier $M$, Collman RG, Doms RW: A dual-tropic primary HIV-I isolate that uses fusin and the beta-chemokine receptors CKR-5, CKR-3, and CKR-2b as fusion cofactors. Cell 1996, 85(7): II49-II58.

12. Dragic T, Litwin V, Allaway GP, Martin SR, Huang Y, Nagashima KA Cayanan C, Maddon PJ, Koup RA, Moore JP, Paxton WA: HIV-I entry into CD4+ cells is mediated by the chemokine receptor CC-CKR-5. Nature 1996, 38 I (6584):667-673.

13. Feng Y, Broder CC, Kennedy PE, Berger EA: HIV-I entry cofactor: functional cDNA cloning of a seven-transmembrane, $G$ protein-coupled receptor. Science 1996, 272(5263):872-877.

14. Bjorndal A, Deng H, Jansson M, Fiore JR, Colognesi C, Karlsson A, Albert J, Scarlatti G, Littman DR, Fenyo EM: Coreceptor usage of primary human immunodeficiency virus type $I$ isolates varies according to biological phenotype. Journal of Virology 1997. 7 I ( I 0):7478-7487.

15. Connor RI, Sheridan KE, Ceradini D, Choe S, Landau NR: Change in coreceptor use coreceptor use correlates with disease progression in HIV-I--infected individuals. Journal of Experimental Medicine 1997, I85(4):62I-628.

16. Jansson M, Backstrom E, Bjorndal A, Holmberg V, Rossi P, Fenyo EM, Popovic M, Albert J, Wigzell $\mathrm{H}$ : Coreceptor usage and RANTES sensitivity of non-syncytium-inducing HIV-I isolates obtained from patients with AIDS. I Hum Virol 1999, 2(6):325-338.

17. de Roda Husman AM, van Rij RP, Blaak H, Broersen S, Schuitemaker $\mathrm{H}$ : Adaptation to promiscuous usage of chemokine receptors is not a prerequisite for human immunodeficiency virus type I disease progression. J Infect Dis 1999, 180(4): I 106-IIII5.

18. Liu SL, Schacker T, Musey L, Shriner D, McElrath MJ, Corey L, Mullins $\mathrm{Jl}$ : Divergent patterns of progression to AIDS after infection from the same source: human immunodeficiency virus type I evolution and antiviral responses. I Virol 1997, 7 I(6):4284-4295

19. Ganeshan S, Dickover RE, Korber BT, Bryson YJ, Wolinsky SM: Human immunodeficiency virus type I genetic evolution in children with different rates of development of disease. J Virol 1997, 7 I(I):663-677.

20. Delwart EL, Pan H, Sheppard HW, Wolpert D, Neumann AU, Korber $B$, Mullins Jl: Slower evolution of human immunodeficiency virus type I quasispecies during progression to AIDS. J Virol 1997, 7 I( I 0):7498-7508.

21. Delwart EL, Sheppard HW, Walker BD, Goudsmit J, Mullins Jl: Human immunodeficiency virus type I evolution in vivo tracked by DNA heteroduplex mobility assays. J Virol 1994, 68(10):6672-6683.

22. Lukashov VV, Kuiken CL, Goudsmit J: Intrahost human immunodeficiency virus type $I$ evolution is related to length of the immunocompetent period. J Virol 1995, 69(I I):69|I-69|6.

23. Shioda T, Oka S, Xin X, Liu H, Harukuni R, Kurotani A, Fukushima M, Hasan MK, Shiino T, Takebe $Y$, Iwamoto A, Nagai $Y$ : In vivo sequence variability of human immunodeficiency virus type I envelope gp | 20: association of $\mathrm{V} 2$ extension with slow disease progression. J Virol I997, 7 I(7):487| I-488 I

24. Wolfs TF, de Jong J Van den Berg H, Tijnagel JM, Krone WJ, Goudsmit J: Evolution of sequences encoding the principal neutralization epitope of human immunodeficiency virus $I$ is host dependent, rapid, and continuous. Proc Natl Acad Sci U S A 1990, 87(24):9938-9942.

25. Wolinsky SM, Korber BT, Neumann AU, Daniels M, Kunstman KJ, Whetsell AJ, Furtado MR, Cao Y, Ho DD, Safrit JT: Adaptive evolution of human immunodeficiency virus-type I during the natural course of infection. Science 1996, 272(526 I):537-542.

26. Goodenow M, Huet T, Saurin W, Kwok S, Sninsky J, Wain-Hobson S: HIV-I isolates are rapidly evolving quasispecies: evidence for viral mixtures and preferred nucleotide substitutions. J Acquir Immune Defic Syndr 1989, 2(4):344-352.

27. Markham RB, Wang WC, Weisstein AE, Wang Z, Munoz A, Templeton A, Margolick J, Vlahov D, Quinn T, Farzadegan H, Yu XF: Patterns of HIV-I evolution in individuals with differing rates of CD4 T cell decline. Proc Natl Acad Sci U S A 1998, 95(2I):|2568-I2573.

28. McNearney T, Hornickova Z, Markham R, Birdwell A, Arens M, Saah $A$, Ratner $L$ : Relationship of human immunodeficiency virus type I sequence heterogeneity to stage of disease. Proc Nat Acad Sci U S A 1992, 89(2I): 10247-1025 I.

29. Shankarappa R, Margolick JB, Gange SJ, Rodrigo AG, Upchurch D, Farzadegan H, Gupta P, Rinaldo CR, Learn GH, He X, Huang XL, Mullins $\mathrm{Jl}$ : Consistent viral evolutionary changes associated with the progression of human immunodeficiency virus type $I$ infection. J Virol 1999, 73( I 2): 10489-10502.

30. Herbeck JT, Nickle DC, Learn GH, Gottlieb GS, Curlin ME, Heath L, Mullins Jl: Human Immunodeficiency Virus Type I env Evolves toward Ancestral States upon Transmission to a New Host. J Virol 2006, 80(4): I637-1644.

31. Li S, Juarez J, Alali M, Dwyer D, Collman R, Cunningham A, Naif HM Persistent CCR5 utilization and enhanced macrophage tropism by primary blood human immunodeficiency virus type $\mathrm{I}$ isolates from advanced stages of disease and comparison to tissue-derived isolates. Journal of Virology 1999, 73(I 2):974|-9755

32. Churchill M, Sterjovski J, Gray L, Cowley D, Chatfield C, Learmont J, Sullivan JS, Crowe SM, Mills J, Brew BJ, Wesselingh SL, McPhee DA, Gorry PR: Longitudinal analysis of nef/long terminal repeatdeleted HIV-I in blood and cerebrospinal fluid of a long-term survivor who developed HIV-associated dementia. J Infect Dis 2004, 190(| 2):218|-2186

33. Jekle A, Schramm B, Jayakumar P, Trautner V, Schols D, De Clercq E, Mills J, Crowe SM, Goldsmith MA: Coreceptor phenotype of natural human immunodeficiency virus with nef deleted evolves in vivo, leading to increased virulence. J Virol 2002, 76(14):6966-6973.

34. Alexander L, Illyinskii PO, Lang SM, Means RE, Lifson J, Mansfield K, Desrosiers RC: Determinants of increased replicative capacity of serially passaged simian immunodeficiency virus with nef deleted in rhesus monkeys. J Virol 2003, 77( I 2):6823-6835.

35. Crowe SM, Ho DD, Marriott D, Brew B, Gorry PR, Sullivan JS, Learmont J, Mills J: In vivo replication kinetics of a nef-deleted strain of HIV-I. Aids 2005, 19(8):842-843.

36. Gorry PR, Bristol G, Zack JA, Ritola K, Swanstrom R, Birch CJ, Bell JE, Bannert N, Crawford K, Wang H, Schols D, De Clercq E, Kunstman K, Wolinsky SM, Gabuzda D: Macrophage Tropism of Human Immunodeficiency Virus Type I Isolates from Brain and Lymphoid Tissues Predicts Neurotropism Independent of Coreceptor Specificity. J Virol 200I, 75(2I): 10073-10089.

37. Donzella GA, Schols D, Lin SW, Este JA, Nagashima KA, Maddon PJ, Allaway GP, Sakmar TP, Henson G, De Clercq E, Moore JP: AMD 1 100, a small molecule inhibitor of HIV-I entry via the CXCR4 co-receptor. Nat Med 1998, 4(I):72-77.

38. Schols D, Struyf S, Van Damme J, Este JA, Henson G, De Clercq E: Inhibition of T-tropic HIV strains by selective antagonization of the chemokine receptor CXCR4. J Exp Med 1997 , | 86(8): | $383-1388$.

39. Baba M, Nishimura O, Kanzaki N, Okamoto M, Sawada H, lizawa $Y$, Shiraishi M, Aramaki Y, Okonogi K, Ogawa Y, Meguro K, Fujino M: A small-molecule, nonpeptide CCR5 antagonist with highly potent and selective anti-HIV-I activity. Procedings of the National Academy of Sciences USA 1999, 96( I0):5698-5703.

40. Yi Y, Shaheen F, Collman RG: Preferential use of CXCR4 by R5X4 human immunodeficiency virus type $I$ isolates for infection of primary lymphocytes. J Virol 2005, 79(3): $1480-1486$.

4I. Zhang L, Chung C, Hu BS, He T, Guo Y, Kim AJ, Skulsky E, Jin X, Hurley A, Ramratnam B, Markowitz M, Ho DD: Genetic characterization of rebounding HIV-I after cessation of highly active antiretroviral therapy. / Clin Invest 2000, 106(7):839-845.

42. Wang B, Spira TJ, Owen S, Lal RB, Saksena NK: HIV-I strains from a cohort of American subjects reveal the presence of a V2 region extension unique to slow progressors and non-progressors. Aids 2000, I 4(3):213-223.

43. Jensen MA, $L i$ FS, van 't Wout $A B$, Nickle $D C$, Shriner $D$, $H e H X$, McLaughlin S, Shankarappa R, Margolick JB, Mullins Jl: Improved coreceptor usage prediction and genotypic monitoring of R5-to-X4 transition by motif analysis of human immunodeficiency virus type I env V3 loop sequences. J Virol 2003, 77(24): 13376-13388.

44. Milich L, Margolin BH, Swanstrom R: Patterns of amino acid variability in NSI-like and SI-like V3 sequences and a linked change in the CD4-binding domain of the HIV-I Env protein. Virology 1997, 239(1):108-118. 
45. Briggs DR, Tuttle DL, Sleasman JW, Goodenow MM: Envelope V3 amino acid sequence predicts HIV-I phenotype (co-receptor usage and tropism for macrophages). Aids 2000, I 4(I 8):2937-2939.

46. Ghaffari G, Tuttle DL, Briggs D, Burkhardt BR, Bhatt D, Andiman WA, Sleasman JW, Goodenow MM: Complex Determinants in Human Immunodeficiency Virus Type I Envelope gp I20 Mediate CXCR4-Dependent Infection of Macrophages. J Virol 2005, 79(2I):|3250-|326|.

47. Gorry PR, McPhee DA, Wesselingh SL, Churchill MJ: Macrophage tropism and cytopathicity of HIV-I variants isolated sequentially from a long-term survivor infected with nef-deleted virus. The Open Microbiology Journal 2007, I:I-7.

48. Gorry PR, Taylor J, Holm GH, Mehle A, Morgan T, Cayabyab M, Farzan M, Wang H, Bell JE, Kunstman K, Moore JP, Wolinsky SM, Gabuzda D: Increased CCR5 affinity and reduced CCR5/CD4 dependence of a neurovirulent primary human immunodeficiency virus type I isolate. Journal of Virology 2002, 76( I 2):6277-6292.

49. Kolchinsky P, Kiprilov E, Bartley P, Rubinstein R, Sodroski J: Loss of a single $\mathrm{N}$-linked glycan allows CD4-independent human immunodeficiency virus type $I$ infection by altering the position of the gpl20 VI/V2 variable loops. J Virol 200I, 75(7):3435-3443.

50. Kolchinsky P, Kiprilov E, Sodroski J: Increased neutralization sensitivity of CD4-independent human immunodeficiency virus variants. J Virol 200I, 75(5):204I-2050.

5I. Wyatt R, Kwong PD, Desjardins E, Sweet RW, Robinson J, Hendrickson WA, Sodroski JG: The antigenic structure of the HIV gp I 20 envelope glycoprotein. Nature 1998, 393(6686):705-7II.

52. Wyatt R, Sullivan N, Thali M, Repke H, Ho D, Robinson J, Posner M, Sodroski J: Functional and immunologic characterization of human immunodeficiency virus type I envelope glycoproteins containing deletions of the major variable regions. J Virol 1993, 67(8):4557-4565.

53. Gorry P, Purcell D, Howard J, McPhee D: Restricted HIV-I infection of human astrocytes: potential role of nef in the regulation of virus replication. Journal of Neurovirology 1998, 4(4):377-386.

54. Gray L, Sterjovski J, Churchill M, Ellery P, Nasr N, Lewin SR, Crowe SM, Wesselingh S, Cunningham AL, Gorry PR: Uncoupling coreceptor usage of human immunodeficiency virus type I (HIV I) from macrophage tropism reveals biological properties of CCR5-restricted HIV-I isolates from patients with acquired immunodeficiency syndrome. Virology 2005, 337:384-398.

55. Gorry PR, Zhang C, Wu S, Kunstman K, Trachtenberg E, Phair J, Wolinsky S, Gabuzda D: Persistence of dual-tropic HIV-I in an individual homozygous for the CCR5 Delta 32 allele. Lancet 2002, 359(9320): 1832-1834.

56. Klevytska AM, Mracna MR, Guay L, Becker-Pergola G, Furtado M, Zhang $\mathrm{L}$, Jackson JB, Eshleman $\mathrm{SH}$ : Analysis of length variation in the VI-V2 region of env in nonsubtype B HIV type I from Uganda. AIDS Res Hum Retroviruses 2002, I 8(I I):79I-796.

57. Derdeyn CA, Decker JM, Bibollet-Ruche F, Mokili JL, Muldoon M, Denham SA, Heil ML, Kasolo F, Musonda R, Hahn BH, Shaw GM, Korber BT, Allen S, Hunter E: Envelope-constrained neutralizationsensitive HIV-I after heterosexual transmission. Science 2004, 303(5666):2019-2022.

58. Gao F, Morrison SG, Robertson DL, Thornton CL, Craig S, Karlsson G, Sodroski J, Morgado M, Galvao-Castro B, von Briesen H, et al.: Molecular cloning and analysis of functional envelope genes from human immunodeficiency virus type I sequence subtypes A through G. The WHO and NIAID Networks for HIV Isolation and Characterization. IVirol 1996, 70(3): |65 I-I667.

59. He J, Chen Y, Farzan M, Choe H, Ohagen A, Gartner S, Busciglio J, Yang X, Hofmann W, Newman W, Mackay CR, Sodroski J, Gabuzda D: CCR3 and CCR5 are co-receptors for HIV-I infection of microglia. Nature 1997, 385(66I7):645-649.

60. Ohagen A, Devitt A, Kunstman KJ, Gorry PR, Rose PP, Korber B, Taylor J, Levy R, Murphy RL, Wolinsky SM, Gabuzda D: Genetic and functional analysis of full-length human immunodeficiency virus type I env genes derived from brain and blood of patients with AIDS. Journal of Virology 2003, 77(22): 12336-I 2345.

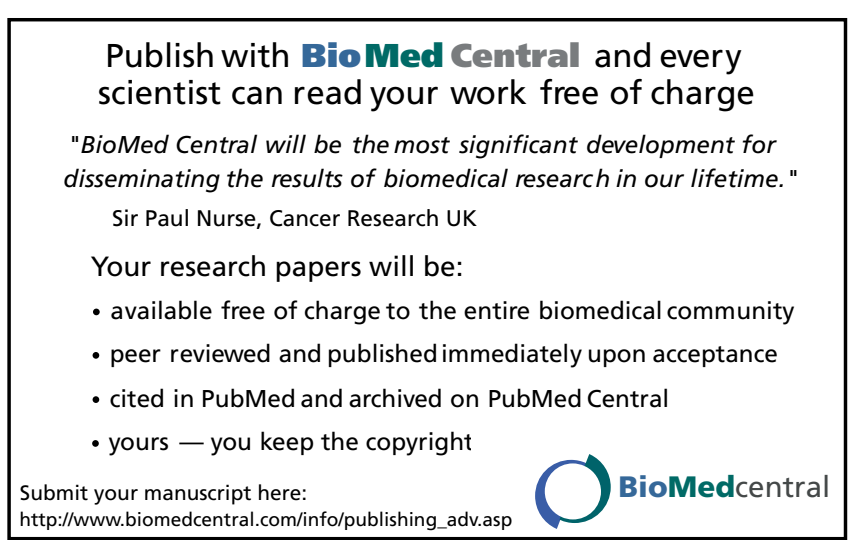

